\title{
Evaluation of rice and sweetcorn-based cropping system for rainfed upland ecosystem of Eastern India
}

\section{V.P. UBARHANDE AND S.N. PANDA}

Received : 18.03.2014; Revised : 15.07.2014; Accepted : 01.08.2014

See end of the Paper for authors' affiliation

Correspondence to :

V.P. UBARHANDE

Department of Agricultural

Food Engineering, Indian

Institute of Technology,

KHARAGPUR (W.B.) INDIA
ABSTRACT : In the eastern India, rainfed area occupies nearly two-third of its total cultivable area. Rice is the predominant crop which is no more beneficial to farmers of the region due to its low yield. So there is a need to change in a cropping system and to find better crop substitution which can give more returns to the farmers than the existing system. With this view, the study was conducted at Indian Institute of Technology Kharagpur to evaluate rice and sweetcorn based cropping system for rainfed upland ecosystem of Eastern India. For this purpose two cropping systems, rice-peanut and sweetcorn-peanut were taken into consideration. Two crop growth simulation models viz., CERES-rice and CERES-maize of DSSAT v4.0 (Decision Support System for Agrotechnology Transfer) were used to simulate the rice and maize yield of the region using historical weather data at Indian Institute of Technology Kharagpur for the years 1978 to 2007. The field experiment was carried out and the experimental data of yield components (yield and top weight) for the years 2009 to 2011 were used to calibrate and validate both the models. The comparative assessment of economic feasibility of the cropping systems (rice-peanut and sweetcorn-peanut) was also carried out to identify suitable cropping system for the region. The results of the models validated statistically which revealed that the models can predict the yield components with high accuracy. The net income from 1 hectare for rice-peanut and sweetcorn-peanut cropping pattern was Rs. 64415 and Rs. 90330, respectively. So it was concluded from the study that, for the rainfed upland ecosystem of Eastern India, sweetcornpeanut cropping system was more beneficial than rice-peanut cropping system. Sweetcorn-peanut cropping system can be adopted for the sustainable development in the region.

- KEY WORDS : CERES-maize, CERES-rice, Cropping system, DSSAT v4.0, Rainfed

— HOW TO CITE THIS PAPER : Ubarhande, V.P. and Panda, S.N. (2014). Evaluation of rice and sweetcorn-based cropping system for rainfed upland ecosystem of Eastern India. Internat. J. Agric. Engg., 7(2) : 285-292. 